\title{
Role of Logic and Mentality as the Basics of Wittgenstein's Picture Theory of Language and Extracting Educational Principles and Methods according to this Theory
}

\author{
Kamal Nosrati Heshi ${ }^{1}$ \& Hassanali Bakhtiyar Nasrabadi ${ }^{2}$ \\ ${ }^{1} \mathrm{PhD}$ student In Philosophy of Education, Department of Educational Sciences, Faculty of Educational Sciences \\ and Psychology, University of Isfahan, Isfahan, Iran \\ ${ }^{2}$ Associate Professor, Department of Educational Sciences, Faculty of Educational Sciences and Psychology, \\ University of Isfahan, Isfahan, Iran \\ Correspondence: Hassanali Bakhtiyar Nasrabadi, Associate Professor, Department of Educational Sciences, \\ Faculty of Educational Sciences and Psychology, University of Isfahan, Isfahan, Iran. E-mail: \\ H.nasrabadi@edu.ui.ac.ir
}

Received: November 26, 2015 Accepted: January 8, 2016 Online Published: June 27, 2016

doi:10.5539/ies.v9n7p10 URL: http://dx.doi.org/10.5539/ies.v9n7p10

\begin{abstract}
The present paper attempts to recognize principles and methods of education based on Wittgenstein's picture theory of language. This qualitative research utilized inferential analytical approach to review the related literature and extracted a set of principles and methods from his theory on picture language. Findings revealed that Wittgenstein believed in language as a picture of the real and assumed that the real is reflected in language. He believed that language and mentality are the same and language demonstrates a full picture of mentality. Besides, the world and the language possess a logical structure and this logic rules the world and the language. Later on, his picture theory of language, logic and mentality were used to extract and introduce principles for education as listed here: the reasonability principle, mind involvement principle, matching principle, reasoning principle, creativity principle and formation of mind, comprehensibility principle, liberal thinking principle, and the principle of considering individual differences. Thus, applying the method of concept comprehension, problem oriented method, heuristic method, brainstorming method and finally interactive methods like Socratic question and answer and group discussion method.
\end{abstract}

Keywords: Wittgenstein, language, picture theory of language, logic, mentality, principles of education, method of education

\section{Introduction}

Language and Education are two distinctive characteristics of humans. Their language is a reflection of mentality and creativity and is a tool for interactions with the environment and fellow counterparts. This is the same goal humans are pursuing by education. In fact, the relationship between mentality and logic is an inseparable one. This integrity reveals itself in education so that talking about education will bring up language as mentality. On the other hand, contemporary people living in highly specialized communities find themselves surrounded by problems of communication and understanding. Moreover, modern humans are living in a world full of sophisticated media. This abundance of mass and social media has increased the speed of national and international communications; yet, the question arises if these media help people have better interactions with each other using these technologies or not.

Along with all dramatic changes in recent century and problems associated with communications, education is still drawing attention to itself as a universal trend. In modern days, people with different social and political structure whether developed or underdeveloped, are strongly interested in education in a universal level and it is of extremely high priority compared to other social activities. Moreover, philosophical history of the issue reveals that language is still critical and the relationship between education and language necessitates further studies in the field. Needless to say those modern countries are increasing the realm of their educational activities, strengthen their educational materials and content and continue the evolutionary trends in this area (Moayeri, 1998, pp. 9-12). 
Problems of understanding and communication on one hand and the issue of education as a delicate and specialized matter with various intricacies along with the integral connection between mentality and language and mentality as the axis of any form of education, have made researchers have a deeper look at the subject. This has initiated worldwide attempts to conduct studies on educational issues and problems of a constructive communication. All these studies aim to decode and separate picture from the real on one hand and reach a more beneficial and efficient method for effective communication and a better understanding of the logical relationship between language and mentality on the other hand. Among all these studies, the ones conducted by analytical philosophers could be considered as the most efficient ones. This has gone so far that in some cases the main characteristics of an analytical philosopher is his interest in language and logic. In fact, these two are the most important factors of an efficient communication and as a result better education.

Therefore, Ludwig Wittgenstein is the pinnacle of the evolution in contemporary analytical philosophy. On the one hand, his thoughts and theories had a crucial role in formulating logical positivism in Vienna Circle and beyond it; on the other hand, analytical philosophy and the philosophy of language as it has evolved since the third decade of the $20^{\text {th }}$ century in England and especially Oxford, are indebted to Wittgenstein and his thoughts for their basic theories and systematic motivations (Peters, 2014). In the first period of his thought, Wittgenstein did not concentrate on the syntax of language and what historical course has it taken. He did not try to find if language is formed by words or sounds. Besides, he did not care about physical characteristics of sound or signs of written language. For him, at that early period, the logical form of the language was of great importance. He wondered how language expresses things other than itself and how things could be explained by a language. He wanted to find out how symbols indicate real things, what relationship language has with the real world. He asked himself if language has limits and if the answer is yes then where they are (Wittgenstein, 2002).

Therefore, elaboration on position of Wittgenstein in analytical philosophy as a philosopher whose ideas brought about huge changes in language analysis is of utmost importance for this analysis plays integral roles in education. Accordingly, researchers try to read the books written by him or about him in his early years and investigate his view toward picture language so that educational outcomes especially on principles of education could be extracted. It is worth mentioning that in his second period of scientific life and in his book titled Philosophical Studies, Wittgenstein made changes in his ideas and rejected some of the earlier thoughts in logical-philosophical treatise. However, in his paper named Considerations on Logical Form written for the Aristotelian Association, he demonstrated that basic principles of his earlier treatise are still approved. Nevertheless, this paper presents a major critique to the treatise and this shows his future course of thought (Fan, 2002, pp. 62-63). However, in this study, ideas of young Wittgenstein are investigated under the title of picture theory of language. This paper does not aim to probe Wittgenstein's thought in his older times. In spite of his rejection to some of his earlier ideas, and all the weaknesses he believed his ideas had in the earlier time, the present paper focuses on the key points on education and attempts to highlight them.

\section{Methodology}

Considering the theoretical nature of education under study, the present paper will attempt to investigate and induce educational outcomes of the philosophy of the early Wittgenstein. This may open up new areas to compile a theory of education. This will clearly begin with a closer look over philosophical approaches of the early Wittgenstein and their educational implications. This study on the philosophy of Wittgenstein and its educational implications goes into the category of qualitative studies for it has to descriptive and prescriptive aspects. It is one of the studies aiming to develop a theory as a final goal (Lapassade, 1991, p. 47); thus, it requires maximum levels of interpretation and abstraction and it could be titled as an Interpretive-Abstractive study (Maykut et al., 1995, pp. 122-123).

In order to compile this study and since it is based directly on the relationship between philosophy and education, Smith's approach comes to mind stating that there is a possibility for studying in a specific philosophy and recording whatever related to education to extract educational issues neglected by philosopher and represent plans and suggestions in accordance to his basic philosophy. Smith however, believes that there are no perfect implications for a philosophy and educational approaches for extracting educational implications from a philosophical theory does not pertain objective and predefined rules. Nevertheless, this is the most common method in the philosophy of education (Smith, 1992, p. 79). Thus, the present study follows Smith's approach, discusses the earlier Wittgenstein's perspective toward language, logic and thought, and then, represents their educational implications.

Data collection for this qualitative research is conducted through all four methods suggested by Marshall and Rossman for collecting documents and deeds. Investigating documents is one of the most well-known methods 
available for researchers. Some experts even believe that it is the most comprehensive method for it is an analytical strategy with a higher degree of objectivity compared to other qualitative methods (Marshall \& Rossman, 1998, p. 119).

\subsection{Stages of Conducting the Study}

The documents and deeds under investigation in this study include philosophical works of Wittgenstein and works of other thinkers in the field. The model of investigation could be divided into three stages:

1) Stage of analysis: in this stage, reading and identifying resources along with selecting documents are conducted (Barden, 1996, pp. 107-115).

2) Stage of analyzing content: in this stage, considering the subject matter of the study, variables and categories to be collected and classified are marked together with other aspects to be interpreted (Myring, 2001).

3) Stage of analyzing results and interpreting them: when authentic results are obtained from content analysis, the analyst could acquire his own interpretation and understanding on research questions and purposes (Barden, 1996, pp. 107-115).

In this study, this approach was taken to collect and analyze the data. These data could be classified into three main classes:

A. The data related to the earlier Wittgenstein's ideas on picture language

B. The data related to the role of logic and thought in early Wittgenstein's point of view and their relationship with picture language

C. The section related to educational implications extracted from the earlier Wittgenstein's philosophical system

The point worth considering about third class of data that they will generally be based on rational and content analysis compiled personally by the authors.

\subsection{Society under Study}

The society under study includes first hand resources like books written by Wittgenstein and second hand resources like books, papers, and researches published in the field. The sample selected covers Wittgenstein's works on language and picture language.

\section{Findings}

\subsection{Wittgenstein and Language as Picture}

Younger Wittgenstein believed that language is the picture of the real and the real is reflected in language. In his treatise, he states that Structure is the true writer (Wittgenstein, 2007). Language is the collection of structures, and as he emphasizes in his treatise, set of structures form the language (Wittgenstein, 2007). As a result, language is the picture. In other words, the role of language is to illustrate. As a picture showing an image, structures demonstrate the affairs. When we talk about something and speak about it, in fact we are imagining it. When a structure has familiar words, no further explanation is needed to comprehend the meaning.

I understand the structure without any explanation (Wittgenstein, 2007, pp. 40-41). As a picture demonstrating the image without any need for help, structure does the same. This is inherently deposited in the essence of structure and has the capability to convey the meaning (Wittgenstein, 1997, pp. 40-47). When language is known as a picture, the intricate problem of the relationship between language and the world is solved i.e. a decent response is given to the question of talking about a concept with some words. In his notes, Wittgenstein states that structure can express something as far as it is a picture (Wittgenstein, 2006, p. 51). When a picture is seen, the function of illustration is not questioned for the essence of picture is to illustrate objects. Language is the same. When something is stated, the thing is pictured. This leads to the question of what the language is.

Wittgenstein's general view toward picture is the picture as the model of the real. For him, pictorial elements of a picture are the same as subjects and represent them (Wittgenstein, 2007, pp. 2012-2013). In fact, he believes that the structure is the picture of what it states. In general, the similarity between a picture and a structure is the way they illustrate things. In fact, this illustration is the attributed ratios between language and the real (Fsenkool, 2006, p. 23).

In another note, he states that language is a collection of structures and structures are the picture of the world. Comparing structure with the picture is in fact a real comparison and Wittgenstein emphasizes on structures as 
pictures. He believes that like pictures and their parts and the relation between those parts, structure has parts as well. In his treatise, Wittgenstein states that anything belonging to the picture belongs to the structure (Wittgenstein, 2007). Furthermore, elements and their relation to each other must be comparable and similar to different elements in real world. In case of pictures too, the elements of picture must be comparable with its parts (Wittgenstein, 2007). At this point, Wittgenstein tries to discover the structure of the world using the structure of the language. Sentences and structures have no meaning unless they represent the real and reflect the structure of the world as it is. Now that we have meaningful structures representing the real, reaching the structure of the world from the structure of the language seems quite plausible.

\subsection{The Position of Mentality in Picture Language}

From Wittgenstein's point of view, language covers the mentality and mentality is the mirror of mentality. He states that "the logical picture of the real is mentality" (Wittgenstein, 1992, p. 62). This introduction could be expressed in a more detailed way. Logical picture of the real issue and state of affairs is indeed the thought and mentality. Mentality discovers the logical and reasonable structure of the things taken from the real world. However, Wittgenstein goes beyond this explanation for he believes that the logical picture of affairs is similar to or the same as mentality. This does not mean that mentality and mind prepare the grounds for illustration processes. He assumes that picture is a symbol of picture by itself. In other words, logical picture of affairs is the mentality and mentality of the logical picture. There in fact is isomorphism between mentality and picture and their relationship is in a way that imagination and thinking are the same illustration and when someone says the state of affairs could be thought, it means their picture could be made and therefore, mentality is the same as picture. In other words, and according to Wittgenstein's point of view toward mentality, it could be concluded that mentality is the language and the language is the mentality. This necessitates all borders and limits of language enter the area of language and any verdict true for the language cover the mentality as well (Wittgenstein, 1990, pp. 1-60). The outcome of this coordination is that anything that can be expressed could be thought of and anything that could not be expressed is not worth thinking about. Thus, borders of mentality and language cover each other and their existence is dependent to each other i.e. mentality without language and language without mentality are impossible.

Nonetheless, thinking and imagination have a condition and this condition is logical and sensible plausibility of them. Thinking is for the sensibly possible not the sensibly impossible. Thus, from Wittgenstein's point of view, impossible assumption is impossible and then no power even the power of the most powerful one could be considered for it. This relationship between possibility and mentality is so strong that the possible is defined as something imaginable and takes imaginability as the criterion for recognizing possibility. Therefore, not only could the impossible enter the realm of thinking but also its verbal explanation is impossible for according to Wittgenstein, mentality is the language (Wittgenstein, 1992, p. 62). This belief means talking about the possible suffices for its possibility and its practicality in practice and reality is necessary.

Then, a collection of logical and honest thoughts gives a true and sensible image of the world (Wittgenstein, 1992, p. 62). However, the condition of sensibility of the image of reality or mentality is that the mentality has the same form (Wittgenstein, 1992, p. 63). Besides, Wittgenstein refers to another important point on the relationship with mentality in his treatise. He believes that mentality is a sentence with a single concept and logical image of the real is a sentence with a single concept (Wittgenstein. 1992, p. 62). In this regard, the concept of meaningful sentence should be elaborated. Wittgenstein believes that various sentences in different times and places may have a similar meaning and refer to a single concept just like talking about a rainy weather in different forms. Yet, in seemingly various conditions, mentality, meaning and case are the same. One the contrary, some similar set of words uttered by two different individuals in the same conditions conveys two different meanings. He acknowledges the distinction between two sense and senseless sentence and yet justifies his emphasis on meaningfulness of the sentence.

Although Wittgenstein has a brief mention on this subject, it should be noted that for him, structure is the application and investigation of a mentality (Wittgenstein, 1990, pp. 3-5). A mentality consists of a logical form (Wittgenstein, 1990, p. 4). The location of mentality is mind and propositions are of two positive meaning showing the position of objects and negative meaning representing what an object is not; yet both of them have the same meaning (Wittgenstein, 1990, pp. 463-464). After all structures have no meaning by themselves and are tolls for conveying and probing mentalities.

\subsection{The Position of Logic in Picture Language}

When we consider language as the picture of reality, we should accept the identical nature of language and reality. In order to have this belief, language and the worlds must have a form with which the identical nature 
and form of language and the world are emphasized. In this case, one of them is the image and the other one is the owner of the image i.e. there is a common form between language and the reality of the world.

In other words, an image and the condition it is representing have commonalities to which Wittgenstein gives the title "logical propositions" (Wittgenstein, 1990). Therefore, the link between form and reality, as the picture of reality, is the common logical form between picture (as a practical reality) and what the picture of reality is according to Wittgenstein. For Wittgenstein, language and the world are of a logical structure and this logic rules the world and the language. Wittgenstein believes logic is objective; however, Wittgenstein rejects the metaphysic world and acts against empiricism traditions of England. According to Wittgenstein, logic is the framework and form of the world and the language and for this reason; language is the picture of the world (Mavence, 2009, p. 82).

In Wittgenstein's point of view, logic is not in the same level with other sciences and does not demonstrate anything basically; yet its principle framework propositions it and makes it visible to the language (Mavence, 2009 , p. 23). The point here is that from his point of view, logic does not express the reality and can just demonstrate it; therefore, it objectively reflects the entire universe (Mavence, 2009, p. 23).

In fact, in Wittgenstein's perspective, logic refers to the combination or position of realities beside each other. Logical propositions that have nothing to do with experience are necessary. For him, structures are divided into three categories of necessarily true, necessarily wrong and possibly true. Necessary propositions are the ones that are true or wrong in any condition; yet the possible proposition is the one that is related to the reality and is true or wrong based on an affair. Propositions used in empirical sciences are among these propositions. In these propositions, no necessity exists and even if there is a generality, it is a casual one. In Wittgenstein's point of view, logical affairs are definitely apart from empirical affairs and are not based on them. In his treatise, Wittgenstein states that logic has priority over experience and the question of how (Wittgenstein, 2007, pp. 150-551). Wittgenstein believes that not only logical propositions are not based on experience but also experience cannot approve or disprove logical propositions. Not only is a logical case deniable by experience, but also, experience cannot approve of it as well (Wittgenstein, 2002). Therefore, logic could only be demonstrated not to be stated. Alongside all these talks, Wittgenstein tries to relate objects using a definite model and this definite model consists of condition, skeleton, framework and structure of the objects according to the rules of logic. Logic determines possible conditions; however, their objective occurrence has nothing to do with logic. In other words, the necessity for logical inference or the necessity for a logical truth has not relationship with what occurs in real world and anything occurring in the objective world is an incident. To put it more simply, it could be said that the rules and logical conditions of a tree imply that the tree is necessarily of a color but logic has nothing to do with the objective occurrence of the color on the tree. According to Wittgenstein, logical form could only be represented not by words or expressions for any proposition demonstrate certain condition of affairs. Therefore, it should possess the logical form it possess in reality. In order to see if the proposition is true or not, its concordance with reality must be investigated. However, its evaluation necessitates understanding its meaning and since no proposition can demonstrate its meaning by itself, then it cannot say anything about its logical form. Nevertheless, Wittgenstein goes further in his claim and says, not only no proposition can talk of its logical form, but also no other proposition can talk about it either.

Language analyzed into the smallest constructing parts of atomic propositions, is formed of images from reality. Thus, propositions could represent the whole reality for propositions and reality has the same logical form and cannot be illogical. It should finally be noted that in young Wittgenstein's point of view, both language and objective world are of logical form and structure and this logical framework is the common point between language and the world. Thus both of them could be considered of the same nature and take one as an image to the other.

\subsection{Educational Implications from Wittgenstein's Views on Picture Language}

Hereby, the principles obtained from what is said above, young Wittgenstein's view toward education methods are discussed in relation to picture language.

First basis: Picture language and logic

Since a comprehensive description was given of the position of logic in picture language and their relationship, in this section, a brief summary is given. It could be said that the first and most important principle in Wittgenstein's point of view is that language is an image of logical reality and logic is the framework and form of language and world. For Wittgenstein, language is the image of reality and reality is represented in language. For him, logical form of the language is of utmost importance and believes that logic is the principle concept of language for logic gives order to the world and language and for this reason, language could be taken as the 
picture of the world (Mavence, 2009, p. 82). He believed that logic could only predict what forms are possible. In his treatise, Wittgenstein states that anything can be real in spite of not being real and this does not necessitate any change in the world; however, there is a relationship between logic and real affairs for affairs occur in a logical atmosphere (Wittgenstein, 2007, p. 10). Considering the above-mentioned basics, following principles could be extracted.

1) Mind involvement principle: One of the major principles of education is to involve learners' minds and encourage them to reason and finally induce. That humans can reach the truth through tools have always been in prominent thinkers' minds. As it was mentioned already, Wittgenstein takes language as the image of reality and believes in compatibility of language and reality. In order to have such belief, language and the world should have a form and structure by which the compatibility is emphasized. One should be the image and the other should be the owner of the image (Wittgenstein, 1990). In other words, Wittgenstein believes that the world and language are of a logical structure and this logic rules the world and language. Therefore, in order to have a better understanding from common logical form and the reason for its existence, creating a problem to involve learners and encourage them to discuss and represent their reasons seems to be vital for enhancing their power of logical reasoning. An intellectual educator must provide the ground for his learner to reach an understanding from debatable concepts and think about the issue consciously. Learners at any level and stage should use their reasoning powers to understand and express logical relationships between affairs. He especially emphasizes that logic does not express the reality and just represent it (Mavence, 2009, p. 23). Therefore, in education, the ultimate goal is to help the learner reach decent perfection, understand the truth behind concepts and grow rationally. The educator has to challenge a learner's mind firstly via representing an absorbing question so that the learner could reach an understanding from the common form of realities in the world and expressing them to depict the education's point of view and the route to its growth. In fact, when learners think about the reason for affairs, they make a reality in their minds logically and obtain the power to gain a comprehensive understanding from the reality of an affair along with a real pictorial language.

2) Accommodation Principle: As Wittgenstein considers language as an image of reality and considers reality reflected in language (Wittgenstein, 2007, p. 401), then, as a result, language is picture. In fact, the idea came to his mind when he examined a sketch of an accident. He noticed that the sketch matches real houses and cars and is their image indeed. In fact, the components of the case form its structure and according to the reality existing in the world, there is a common logical form between them (Wittgenstein, 2006, pp. 49-50). Therefore, the image of the reality must match the image created by language. The same story is true for education for a learner must understand logical images to form a picture matching reality and then use his reasoning and mentality to change it into an image using the language.

3) Thinking and Mentality Principle: one of the most basic principles of all areas is the thinking and mentality principle. Considering Wittgenstein's belief in logical propositions as the frameworks of the world (Wittgenstein, 2007), logical thinking becomes an essential part of comprehending all the concepts in the field of education. Moreover, Wittgenstein refers to the relationship between logic and mathematics and thinks of mathematics as an example of real entities in the world (Wittgenstein, 2007). Thus, the power of mind and mentality must be considered fundamental in comprehending reality. In fact, since all elements and stages of education in the case of comprehending reality of affairs have deep and inseparable connection with each other, and since thinking and mentality are distinctive humanistic features, education cannot be discussed without taking thinking and mentality into account and humans represent what they have learnt through thinking and mentality using language. Then they discover what they have to find. Accordingly, for Wittgenstein, everything could be discussed through logic and a logical affair could be represented objectively (Wittgenstein, 2007). Therefore, according to thinking and mentality principle, the power of intellection and mentality provide the ground for logical thinking so that the learner commences researching and looks for reasons avoiding mere transmission of materials. This is the concept Wittgenstein attempts to elaborate through logic and logical combination. Thus, the concept of thinking in this paper refers to purposeful thinking based on a set of rules and frameworks. These rules are logical and guarantee that thinking is sufficient for reaching the purpose separating it from other affairs. According to this principle, in case individuals follow logical principles and wisdom, fewer or no problems will hinder their road to reach intermediate and final goals.

4) Creativity and Mind Formation Principle: Wittgenstein separates sciences from logic and believes that it is the key factor in the formation of the world. As it was mentioned earlier, for him, logic does not demonstrate anything but it forms the world and makes it visible through language. In this regard, he writes "logic does not express the reality but gives it objective reflection through language (Mavence, 2009, p. 23). Considering this quote from Wittgenstein, we could conclude that any learner wishing to depict a logical image of the reality 
using language, must possess creativity and form a dynamic mind. On the other hand, comprehending the logical relationship in world around humans is need of a dynamic mind capable of understanding these relationships and simple expression of those relationships in order to overcome the problems arise. There is a power in humans with which they can realize what they create in their minds giving it a real existence and making logical relationships with their creations and the world around them (Hussaini \& Sayid, 2002, p. 89). However, although creativity is essential for understanding the reality, comprehending the relationships between these realities seems to be of more vital importance for training creative faculties in children, in its early stages, helps them have systematic minds in other fields of their lives (Cool, Translated by Mofidi, 1995, pp. 262-263). Besides, a motivating and encouraging atmosphere helps improve creativity in children and an authoritarian environment emphasizing on order and too much regulatory hinders creativity.

\section{Education Models}

Hereby, education models taken from the first principles and education principles are discussed.

1) Attaining Concept Model: according to the relationship between language and logic, logic is the framework of the world and any reality has a logical common image with its image. Accordingly, considering the creativity and mind formation principle, understanding the logical relationship between components of reality requires creative faculties of mind. When Wittgenstein says the world is my world (Wittgenstein, 2007) he ascertains that thinking and mentality are strengthened along with the reasoning principle. The reason is that the world an individual living in contemplates on logical relationships based on the growth of creativity, thinking, mentality and the reasoning power he has developed. Accordingly, the method of acquiring a concept for educating individuals is advised to be in a way that increases creativity and learning stability, along with thinking, mentality and theorizing assisted by reasoning.

The model for acquiring the concept from family is data processing. This family emphasizes $\mathrm{n}$ the inherent interest in humans for understanding the world through collection and systematization of the data and offering solutions using concepts created by language. Since the main goal of the relationship between the language of picture and logic based on Wittgenstein's view of the relationship between common logical image of the reality and its image (Wittgenstein, 1990) is to find a logical form, the pattern by which a concept is sought and discovered is used to distinguish the instances apart from stratified instances. In other words, in this model, learners are asked to separate and distinguish common forms of the components in order to reach a better understanding from logical relationships between components (Ahadian, 2009). This model of education has the following advantages. It increases the power of mentality and logical reasoning and comprehension in learners and improves their tolerance for ambiguities for a better logical understanding from reality and its picture requires patience and a mind that can use creative faculties to reach a common form from the material taught. This eventually ends in a better logical deduction in learners, creating a puzzle for them and a stronger motivation for learning.

2) Problem-based Method: problem based teaching method is formed based on the theory that learners have the capability to understand the world. In his view toward understanding the reality of the world, Wittgenstein says in the world, a picture and the reality it represent possess commonalities called image or the logical form of the reality (Wittgenstein, 1990). According to this view, understanding the reality of the world requires an individual to reach a common form of the image and the condition it is representing. Then, the educator should ask challenging questions from his learners to create ambiguities for them and this gives the learner the chance to create the same image in their minds and then analyze and comprehend the logical relationships in the components of the problem and make a proper decision to solve the problem.

This method corresponds to the problems existing in the real world. According to the creativity and mind formation principle in response to these problems, learners are encouraged to learn special knowledge through searching and, unlike verbal expression learning and according to reasoning principle, find the relationship between components of reality (Sha'bani, 2007) in order to compare the image in his mind and express it through the realities in their minds. Therefore, the learner finds practical solutions for the problems he faces.

3) Discovery method: considering the above-mentioned points, realities of the world are all recognizable. In fact, the ultimate goal Wittgenstein pursues by analyzing the language is to discover the reality of the world through depicting it by language (Wittgenstein, 1990). Having this in mind, the educator must introduce the world to the learners through a method by which the learner discusses his own ideas, considers the solutions and express his conclusion using the results from experiments (Vakilian, 2010, p. 103). These conclusions, expressed in the form of a real situation, could be applied in other conditions in order to reach generalized rules and structures. According to Wittgenstein, when a conclusion is trying to become a general rule, the picture of reality should 
have commonalities with the reality itself. In fact logical structure of the reality is composed of the relationship between its components (Wittgenstein, 1992, p. 50) and since in the discovery method, the aim is to find the reality through logical relationships, then, according to the thinking and though principle, the learner actively engages in discovering the reality. The reason is that, according to this principle, thinking in its general sense is trying to discover the unknown and solve the problem; yet, in the logical sense, thinking is the systematized and logical route from the realities in mind and discovering the unknown (Hashemi, 2003, p. 94). Thus, in order to lead human mind toward a systematic and logical route, conditions must be provided for the learner to engage himself with the issue.

\section{Second basis: Picture Language and Mentality}

In Wittgenstein's point of view, language is the picture of mentality i.e. the role of language is to depict the mentality (Wittgenstein, 2007, p. 213). He states, "Language covers the society with mentality and thought reflects language; in other words, logical representation of mentality is through language" (Wittgenstein, 1992, p. 62). Considering this, following principles could be extracted:

1) Liberalism Principle: Liberation is the necessary condition for salvation of individuals in any society; however, this does not mean that in the most liberal conditions, all individuals think in the same way and act accordingly. The individual's mentality depends on his world and his world is his mentality (Wittgenstein, 1992, p. 17). This is the same point Wittgenstein tries to make. Not everybody has the same aptitudes but they can reach to the perfection their aptitude deserves. According to Wittgenstein, language reflects the mentality (Bochenski, 1992, p. 6). Then, if an individual possesses a liberal mentality, and has a liberal view toward incidents and realities, he can express it in a decent way and as a result present the picture. From the point of view of education, liberalism, especially liberal thinking, is necessary for individuals yearning to develop stronger mental faculties and better verbal expression. Lack of liberation is a great barrier for human's personality growth (Sanaei, n.d., pp. 11-12). A large portion of human personality is his mentality and language can express those mentalities. From a philosophical perspective, liberation and liberalism, like education, are among the most critical rights of humans; therefore, liberalism in education can develop a human who can use his liberty to train his faculties and strengthen his aptitudes.

2) Comprehensiveness Principle: Since Wittgenstein believes in inherent unity between language and mentality, the necessity for a comprehensive educational system is felt. This system should cover mentality and disciplining it on the one hand and language and empowering it on the other hand. It should also supervise both of them at the same time for, according to Wittgenstein, mentality and language must cooperate in a balanced way (Wittgenstein, 1992, p. 31). Thus, these two aspects of human life are trained together at the same time and should work together to help each other reach the perfect recognition of reality through considering all individual, cognitive, social etc. sides of life. Moreover, in educational system extracted from Wittgenstein's points of view, it is not sensible to focus on mentality and mental faculties only. He emphasizes that empowering mind and mentality along with strengthening language and speaking faculty are two vital parts of education.

3) The Principle of Considering Personal Differences: from Wittgenstein's perspective, borders of my language are borders of my world and my world is my mentality (Bochenski, 1992, p. 6). In other words, any mentality can develop based on personal traits and therefore, any individual has his own thinking system and the existence of personal differences must be acknowledged paid attention to.

Considering personal differences help both mentality and language become a uniform procedure for all people and turn idiosyncratic according to individuals. It also could be concluded that personal traits are relative to individuals themselves and the growth rate in both mental and physical way. Thus, considering personal differences in education is an indispensible factor. Educators must not use a single method of teaching or consider all their learners the same. He must take various approaches in his teaching and try to consider his learners' needs, their intellectual faculties and mental growth along with their verbal strengths in his teaching practices. According to Wittgenstein, honest and logical mentalities are real, truthful and logical images from the world (Wittgenstein, 1992, p. 62). Accordingly, the teacher must consider the growth environment along with the level of learners' growth and create honest and logical mentalities in individuals' minds so that everybody can make a real and logical image out of his own world.

\section{Education Models}

In this section, education models based on the second basic principle and above mentioned preliminaries are discussed.

1) Brainstorming Model: Educational psychologists and educators believe that according to the principle of 
personal differences, learning condition must be ordered in a way that everybody learns based on his mental abilities and verbal aptitudes. Besides, according to liberalism principle, any individual with liberal mentalities and liberal understanding from incidents with a decent way of expressing them will have a powerful mind and as a result a powerful language and since Wittgenstein believes that mentality is the language and language is the mentality (Wittgenstein, 2002, p. 16), this goal can be achieved with a model like brainstorming. Brainstorming has two basic principles which can help an educator reach what Wittgenstein had in mind considering the fact that education in Wittgenstein's point of view concentrates on mentality and language and tries to strengthen them so that they are identical.

The first principle is based on the variety of ideas. Variety of ideas activates the part of the brain related to creativity so that it can overcome its judgmental approach. The second principle is that quantity increases quality i.e. the more the number of suggestions are, the higher the possibility of reaching a decent solution is (Fazli, n.d. 76). In fact, learners use this model to improve their mentality, strengthen their evaluation and judgment and finally learn to express themselves in an optimum way. In this model, expression of ideas is free and direct providing the requirements of liberalism in Wittgenstein's points of view. This model encourages participants in a meeting to give whatever suggestion coming to their minds. Thus, in a brainstormed meeting, all members must have the courage to express their ideas and suggestions.

2) Interactive Teaching Models: interactive teaching models emphasize on the process of democracy and other cognitive skills like thinking and analyzing so that the possibility of a democratic atmosphere increases (Miller, 1983, pp. 57-63). In this model, three dynamic dimensions of exploration, unification of mentality and language and elevation are the main focus of all activities and interaction among these three dimensions help the learners have an active mind rich with knowledge along with a dynamic language. In this regard, learner is an individual empowered to utilize his rational aptitudes in his contact with social and scientific issues. This learner could analyze general problems rationally and move the barriers of mentality to his language to depict them and this is exactly what Wittgenstein had in mind (Wittgenstein, 2002: 14). In this model, the concept of interaction is vital and necessitates a mutual, dynamic and liberal relationship between learners and the educational environment as a purposeful environment facilitating freedom of mentality (Sha'bani, 2007, p. 243). Since Wittgenstein believes that language and mentality are identical, empowering one will strengthen the other one. In general, in these models, educational opportunities must end in self-renovation i.e. new experiences should help mental growth and this will as a result improve learners' verbal ability to express his ideas. Here are two of the methods:

A- Questioning (Socratic) Method: questioning is the method by which an educator encourages the learner think about a new concept of express a new idea. In this method, the learner tries to use mental activities to move from active to passive and state his ideas as the response. In fact, the goal of questioning is to motivate thinking, interests, reasoning power, verbal ability and create self confidence in learners. Considering Wittgenstein's belief in identical nature of language and mentality (Wittgenstein, 1992, p. 7), it could be concluded that this model gives the learner the power of reasoning and expression. In other words, the learner thinks about a subject, discusses it with other learners and provides the right atmosphere for freedom of expression from other learners. The educator in this environment recognizes learners' stand points and reasoning powers and this will help him have a better understanding from their aptitudes. In this environment, the educator encourages the learner to think about a novel concept and express it. In fact, this technique is a decent tool for evaluating learners' understanding from various concepts.

B- Group Discussion Method: this method is a systematic and orderly conversation on a specific topic commonly interesting to everybody in this group discussion. In this method, the educator poses a topic or an interesting subject and learners study about it, express their opinions, and reach conclusions (Sha'bani, 2007, p. 257). Learners participate in these discussions actively and take the responsibility for learning. Considering Wittgenstein's idea about logical image of a reality as mentality (Wittgenstein, 1992, p. 62), learners must try to reach the reality logically and at the same time express their ideas with their language. Logical framework and reasoning emphasizing liberalism are two major requirements of group discussions. Besides, considering comprehensiveness principle, and emphasizing on simultaneous growth of language and mentality, discussions facilitate expression of realities, while defending scientific concepts along with systematizing ideas from everybody whether wrong or right and evaluate these ideas objectively. In other words, discussion group is a method that gives learners the opportunity for expressing experiences, ideas and beliefs freely and helps them depict their mentalities using valid documents using their verbal aptitudes. This language possesses criteria of picture language and does not overrule them. 


\section{Conclusion}

A brief look at the life of people in modern times demonstrates that people are living at the age of communication and understanding; thus, language is an important connecting factor in their lives and education as a crucial need for humankind in their venture toward perfection could not be of any effect without effective communication. Considering the utmost importance of education, scholars in different field including analytical philosophy have discussed this and the present study attempted probe thoughts of young Ludwig Wittgenstein as a revolutionary approach toward language and the following conclusions were drawn.

Young Wittgenstein founded a method in criticizing language and its structure and content while avoiding traditional philosophical discussions. He revealed what he had in mind in his acclaimed treatise. His efforts in the field of language are of great importance for they limited the circle of knowledge and this could only be done by language and other meaningful criteria. In the first era of Wittgenstein' thinking, the important point for him is to investigate logical form of language or the view of language toward things other than language. In other words, how to demonstrate things with a set of words and its demonstration of various objects in relation to the world and the limits of language are among other important points Wittgenstein tries to make in his early years. In his perspective, language is the image of reality and language is the image of the world. Wittgenstein tries not to fall in the trap of senselessness and analyzes language, sentences and words accordingly. The logical form of language is of vital importance for Wittgenstein. He believes that a sentence is an image of what it tries to demonstrate literally and states that there are similarities between an image and a sentence in showing an image. In his point of view, language and the objective world are of a logical structure and this logical framework is the common point between language and the world. Therefore, language and the world could be considered identical and consider one as an image for the other one.

For Wittgenstein, language and mentality are the same and language is a perfect mirror for mentality. In other words, logical form of the language is the logical form of mentality and the borders of language are the same borders of mentality. The result for this coordination is that anything that could be stated could be thought and anything that could not be stated does not deserve to be thought about.

Eventually, various methods were extracted from Wittgenstein's views toward language and education of learners. Principles have does and don'ts in any approach of education considered to be the framework of the guide to education of learners by educators. To put it another way, principles are based on the philosophical views of a philosopher and help practical methods of education to be inferred. Thus, these principles, considering the results from this study, include reasoning, accommodation, creativity and mind analysis, liberalism, comprehensiveness and considering personal differences are principles of Wittgenstein's perspective and following methods could be driven from these principles: methods of comprehending the concept along with problem-based, discovery and brainstorming methods. Interactive methods are questioning and group discussion methods. In the discussion on methods, it should be noted that studying the methods induces self-renovation with acquiring new experiences through mental growth and at the same time gives the learners the power of reasoning, and liberalism to express what they have in mind. In conclusion, it could be said that young Wittgenstein's views on language are extremely important in the field of education for education, in great part, depends on communication and comprehension of the concepts influencing humans' daily life in direct or indirect ways.

\section{References}

Ahmadian, M. (1999). A Guide on teaching methods for education and training. Tehran: Ayizh

Bakhtiar, N. H., \& Noroozi, R. A. (2004). Education, novel approaches and views. Isfahan: Isfahan University Pub.

Barden, L. (1996). Content Analysis. Translated by: Malihe Ashtiani and Muhammad Yamani Doozi Sorkhabi. Tehran: Shahid Beheshti University Pub.

Bocheński, J. M. (2000). Contemporary European Philosophy. Translated by Sharaf-al-Din Khorasani. Tehran: Elmi Farhangi Pub.

Borris, J., \& Marshal, V. (1997). Modern teaching models. Translated by Mohammad Reza Behrangi. Tehran: Taban Pub.

Cool, V. (1995). Education in Preschool years. Translated by Farkhonde Mofidi. Tehran: SAMT Pub.

Fan, K. T. (2002). The concept of philosophy for Wittgenstein. Translated by Kamran Ghara Gozli. Tehran: Markaz Pub.

Farokh, M. H. (2007). Pleasant Motif. Tehran: Aabed Pub. 
Fazli, M. (n.d.). Practical Guide to Active Participation. Tehran: Mehran Pub.

Fesenkol, W. (2006). To say and not to Say. Three Papers on Philosophy of Wittgenstein. Translated by Malek Hussaini. Tehran: Hermes Pub.

Fitjeneshtine, L. F. (1968). Tractatus Logico-Philosophicus, Practical translation with appendices. Translated by Azmi Islam. Cairo: English and Egypt School.

Hashemi, M. (2004). Descipline and Human Personality. Qom: The centre for Publications of Islamic Propagation of Qom Howza.

Hussaini, K., \& Sayid, H. (2002). Creativity/Human's domination in Islamic mysticism and philosophy. Kheradname Sadra Quarterly, 28, 12-25.

Lapassade, G. (1991). L'ethnosociologie. Paris: Merdiens Klincksieck

Marshall, C., \& Rossman, G. B. (1998). Qualitative Researches Method. Translated by Ali Parsaian and Seyed Mohamad Arabi, Tehran: Cultural Researches Office.

Maunce, H. (2009). An Introduction to Wittgenstein Treatise. Translated by Sohrab Alavi Nia. Tehran: Tarhe No Pub.

Maykut, P., \& Morehouse, R. (1995). Beginning Qualitative Research. London: Flamer Press.

Michael, A. P. (2014). Incorporating ACCESS Education Arena Expert panel, Educational philosophy and Theory.

Miller, G. R. (1983). Discursive Communication (An analysis on meaning of discourse). Translated by Ali Zekavati Gharagozloo. Soroosh Pub.

Moayeri, M. T. (1998). Educational Issues. Tehran: Amir Kabir Pub.

Myring, P. (2001). Qualitative Content Analysis-Research Instrument or Mode of Interpretation? Retrieved from http://www.unituebingen.de/qualitative-psychologic/t-WSD1/Mayring-en.htm

Norman, M. (1993). Wittgenstein: A Religious Point of View? Edited with a response by Peter Winch, Copyright by Rout Malcolm, Cornell University Press, Ithaca, New York.

Safavi, A. A. (1992). Principles and techniques of teaching. Tehran: Moaser Pub.

Sanaei, M. (n.d.). Freedom and Discipline (4th ed.). Tehran: Amir-Kabir Pub.

Sha'bani, H. (2007). Education techniques and skills. Tehran: SAMT Pub.

Smith, F. J. (1992). Philosophy of Education. Translated by Saeid Beheshti. Mashad: Astan Ghods Razavi Pub.

Uwe, F. (2002). An Introduction to Qualitative Research. Translated by Abdolrasool Jamshidian, Rezaali Nowruzi, Seyed Ali Seyadat, Qom: Samae Qalam Publication.

White. (2004). The concept of philosophy for Wittgenstein. Translated by Kamran Ghara Gozli. Tehran: Markaz Pub.

Wittgenstein, L. (1990). Tractatus Logico-Philosophicus. Translated by Mahmood Ebadian. Tehran: Jahad Daneshgahi Pub.

Wittgenstein, L. (1992). Tractatus Logico-Philosophicus. Translated by Mir Shams al-Din Adib Soltani. Tehran: Amir Kabir Pub.

Wittgenstein, L. (2002). Tractatus logico philosophicus. Translated by D-F PEARS and Guinness ,London and new York: Routledge.

Wittgenstein, L. (2006). Notes. Translated by Moosa Dibaj \& MAryam Hayat Shahi. Tehran: Amir Kabir Pub.

Wittgenstein, L. (2007). Tractatus Logico-Philosophicus. Translated by Mir Shams al-Din Adib Soltani. Tehran: Amir Kabir Pub.

\section{Copyrights}

Copyright for this article is retained by the author(s), with first publication rights granted to the journal.

This is an open-access article distributed under the terms and conditions of the Creative Commons Attribution license (http://creativecommons.org/licenses/by/3.0/). 